\title{
Clubbing in African patients with pulmonary tuberculosis
}

\author{
P A REEVE, A D HARRIES, W A NKHOMA, D S NYANGULU, J J WIRIMA \\ From the Department of Medicine, Kamuzu Central Hospital, Lilongwe, Malawi
}

Finger clubbing was first discussed in association with pulmonary tuberculosis in $1915^{1}$ but is not included as a feature of the disease in most modern textbooks of medicine. It has been our impression that clubbing is common in adult African patients with pulmonary tuberculosis, and we therefore studied the prevalence of this physical sign and related it to clinical features and nutritional state.

Patients, methods, and results

We studied 100 (67 male) African patients, aged 18-68 years, with sputum positive pulmonary tuberculosis who were consecutively admitted to the chest wards of the Lilongwe hospital. Sputum smears were stained by the Ziehl-Neelsen method for acid fast mycobacteria. Clinical features were documented and in most patients radiology was performed.

Address for reprint requests: Dr A D Harries, Department of Medicine, Kamuzu Central Hospital, PO Box 149, Lilongwe, Malawi, Central Africa.

Accepted 19 January 1987
On admission all patients were weighed and measured in indoor clothes and without shoes. Weight was expressed as a $\times$ percentage of the minimum desirable weight for height $\hat{N}$ (ideal). ${ }^{2}$ Arm circumference was measured with a Dean fibre $-\overrightarrow{-}$ glass tape and triceps skinfold thickness with Harpenden? skinfold calipers at the mid point of the upper arm on theo left or non-dominant side. Arm muscle circumference (AMC) was derived: AMC $(\mathrm{cm})=$ arm circumference $\triangle$ (cm) $-3.14 \times$ triceps skinfold thickness $(\mathrm{cm}){ }^{3}$ All three measurements were expressed as percentages of reference standards for men and women. ${ }^{3}$ Muscle function was assessed by handgrip strength on the left or non-dominant $\Xi$ side, a Harpenden hand grip dynamometer being used; three values were taken and the highest used. The fingers of both hands were assessed independently by two observers (PAR, $\vec{\infty}$ ADH). Clubbing was only recorded as present if there was agreement between the two observers. Clinical features and nutrition were compared between those with and withouto clubbing by the unpaired Student's $t$ test and $\chi^{2}$ test $(1 \mathrm{df})$.

Thirty four subjects had clubbing, and significantly more $\overline{0}$ men than women $(42 \% v<21 \%$; p $<0.05)$. For neithero men nor women were there any significant differences in尺

Clinical and radiographic features and nutritional state of patients with tuberculosis with and without clubbing (means with standard deviations in parentheses for body measurements)

\begin{tabular}{|c|c|c|c|c|}
\hline & \multicolumn{2}{|l|}{ Men } & \multicolumn{2}{|l|}{ Women } \\
\hline & Clubbing & No clubbing & Clubbing & No clubbing \\
\hline $\begin{array}{l}\text { Total number } \\
\text { Mean (SD) age (y) } \\
\text { New:relapsed cases } \\
\text { Length of symptoms (mean) in new cases } \\
\text { Haemoptysis (No }(\%)) \\
\text { Night sweats }(\text { No }(\%))\end{array}$ & $\begin{array}{l}26 \\
42(12) \\
15: 11 \\
5 \mathrm{mo} \\
13(50) \\
15(58)\end{array}$ & $\begin{array}{l}36 \\
42(14) \\
23: 13 \\
6 \mathrm{mo} \\
12(33) \\
23(64)\end{array}$ & $\begin{array}{l}8 \\
42(17) \\
4: 4 \\
6 \text { mo } \\
2(25) \\
2(25)\end{array}$ & $\begin{array}{l}30 \\
34(10) \\
21: 9 \\
6 \mathrm{mo} \\
7(23) \\
15(50)\end{array}$ \\
\hline $\begin{array}{l}\text { Daily sputum volume } \\
\text { Scanty } \\
\text { Egg cup } \\
\text { Half cup } \\
\text { Cup } \\
\text { Cigarette smoking (No }(\%))\end{array}$ & $\begin{array}{c}12 \\
3 \\
6 \\
5 \\
11(42)\end{array}$ & $\begin{array}{l}24 \\
6 \\
5 \\
1 \\
10(28)\end{array}$ & $\begin{array}{l}\frac{6}{1} \\
1 \\
1(12)\end{array}$ & $\begin{array}{l}23 \\
3 \\
3 \\
1 \\
1(3)\end{array}$ \\
\hline $\begin{array}{l}\text { Chest radiographs } \\
\text { Number of patients } \\
\text { No of diseased zones } \\
1-2 \\
3-4 \\
5-6 \\
\text { Volume loss }(\text { No }(\%)) \\
\text { Cavities (No (\%)) }\end{array}$ & $\begin{array}{l}23 \\
2 \\
11 \\
10 \\
11(48) \\
21(91)\end{array}$ & $\begin{array}{l}27 \\
7 \\
7 \\
13 \\
12(44) \\
21(78)\end{array}$ & $\begin{array}{l}6 \\
1 \\
1 \\
4 \\
3(50) \\
5(83)\end{array}$ & $\begin{array}{l}26 \\
4 \\
13 \\
9 \\
11(42) \\
22(85)\end{array}$ \\
\hline $\begin{array}{l}\text { Body measurements } \\
\text { Weight }(\% \text { ideal) } \\
\text { Arm circumference (\% reference) } \\
\text { Arm muscle circumference (\% reference) } \\
\text { Triceps skinfold (\% reference) } \\
\text { Hand grip }(\mathrm{kg})\end{array}$ & $\begin{array}{l}77.2(10.9)^{*} \\
70.1 \quad(8.6)^{*} \\
75.8(9.0)^{*} \\
41.8(10.7) \\
27(8.4)^{*}\end{array}$ & $\begin{array}{l}82.9(10 \cdot 0) \\
76.8(9 \cdot 1) \\
82.4(9 \cdot 8) \\
43.5(15 \cdot 1) \\
32(9 \cdot 6)\end{array}$ & $\begin{array}{l}82 \cdot 2(12 \cdot 3) \\
70 \cdot 5(8 \cdot 1) \\
78 \cdot 9(8 \cdot 2) \\
46 \cdot 2(10 \cdot 7) \\
18(8 \cdot 7)^{*}\end{array}$ & $\begin{array}{l}87.7(11.9) \\
76.5(9.6) \\
80.6(7.8) \\
60.0(25.4) \\
25(7.6)\end{array}$ \\
\hline
\end{tabular}


symptoms or radiographic appearance between those with and without clubbing (table). In men with clubbing there was a significant reduction in weight, muscle mass as judged by arm muscle circumference, and muscle function; while in women muscle function was significantly decreased.

\section{Discussion}

We found that one third of adult Africans with sputum positive pulmonary tuberculosis admitted to hospital showed clubbing, and this physical sign was more common in men than in women. Men with clubbing were significantly more undernourished, particularly with respect to muscle mass and muscle function, than those without clubbing. The smaller numbers of women with clubbing makes nutritional interpretation difficult.

These findings suggest that more debilitating disease is associated with clubbing, and an increased mortality rate reported in patients with clubbing ${ }^{4}$ supports this hypothesis. Although we did not find significant differences in their clinical and radiological features, most of our patients had extensive, cavitating tuberculosis affecting more than three zones of the lungs.
Before the introduction of antituberculosis chemotherapy, clubbing was a frequent finding in American patients with tuberculosis. ${ }^{1}$ Effective and early treatment may prevent the progression of disease and the development of clubbing. Despite its omission from many current textbooks of medicine, our study shows that clubbing is still nevertheless frequently present in African patients with pulmonary tuberculosis.

\section{References}

1 Locke EA. Secondary hypertrophic osteo-arthropathy and its relation to simple club-fingers. Arch Intern Med 1915;15:659-713.

2 Metropolitan Life Insurance Company. Desirable weights for adults. In: Diem K, Lentner C, eds. Scientific tables. Documenta Geigy. 7th ed. Macclesfield: Geigy, 1972:712.

3 Jelliffe DB. The assessment of the nutritional status of the community. Geneva: World Health Organisation, 1966. (WHO Monograph Series, No 53.)

4 Macfarlane JT, Ibrahim M, Tor-Agbidye S. The importance of finger clubbing in pulmonary tuberculosis. Tubercle 1979;60:45-8. 